\title{
Prioritizing Active Learning: An Exploration of Gateway Courses in Political Science
}

Candace C. Archer, Bowling Green State University

Melissa K. Miller, Bowling Green State University

ABSTRACT Prior research in political science and other disciplines demonstrates the pedagogical and practical benefits of active learning. Less is known, however, about the extent to which active learning is used in political science classrooms. This study assesses the prioritization of active learning in "gateway" political science courses, paying specific attention to simulations, structured debates, and the case method. Nearly five hundred individual course syllabi for introductory-level political science courses are examined. Although the level of active learning prioritization is surprisingly low, the dimensions on which it varies suggest opportunities for adoption across subfields and classes of varying size.

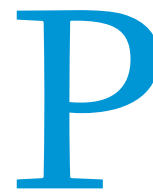

icture a typical introductory-level class in political science. Imagine the classroom itself. It is probably large, perhaps even "stadium-style," with rows of seats ascending away from a small well in which an instructor delivers lectures. Students occupy the many seats in the room, dutifully taking notes from PowerPoint slides, transparencies, or outlines scrawled on a chalkboard. Although time is reserved at the end of each session for questions, little other student-instructor interaction takes place. Exams are interspersed throughout the term to assess student comprehension of instructor-delivered content.

This description may well typify an introductory class from some years ago, but these days, so much attention is being paid to "active learning" that one might assume that a very different model of instruction dominates. After all, colleges and universities have become interested in shifting instruction from a simple "teaching" focus to more active, student-centered "learning" (Barr and Tagg 1995).

Active learning promotes collaboration between students and their instructor. This approach encourages students to participate in the learning process through techniques such as simulations, structured debates, and the case method. The goal of each of these exercises is to "produce learning, develop critical thinking skills, and elicit discovery and the construction of knowledge"

Candace C. Archer is an associate professor of political science at Bowling Green State University. Her research and teaching focus on the areas of international political economy and international organizations. Specifically, her work focuses on global financial issues, global financial crises, and international financial organization responses to crisis. She can be reached at carcher@bgsu.edu.

Melissa K. Miller is an assistant professor of political science at Bowling Green State University, where her teaching and research focus on politics and gender, political participation, political parties, and voter behavior. She can be reached at melissm@bgsu.edu.
(Lantis et al. 2000, 1). This strategy differs from the traditional lecture-driven approach in which an instructor delivers material to relatively passive students who must subsequently demonstrate knowledge on exams.

Numerous studies detail how active learning can be incorporated into political science courses (e.g., Burch 200o; Lantis et al. 2000; Loggins 2009). Political scientists have published various accounts of their positive personal experiences with active learning (e.g., Kelle 2008; Hoffman 2009; Lightcap 2009), and pedagogical benefits have been documented in both political science and other disciplines (e.g., Green and Klug 1990; Carlson and Schodt 1995; Budesheim and Lundquist 1999; Dougherty 2003; Frederking 2005; Shellman and Turan 2006; Mariani 2007; Lightcap 2009). Active learning techniques have also been shown to stimulate student interest in subject matter (Dougherty 2003; Mariani 2007) and attract majors to the discipline (Fox and Ronkowski 1997; Shellman and Turan 2006).

In light of its established benefits, the prioritization of active learning in political science courses warrants examination. In this article, we assess the extent to which active learning is prioritized in common "gateway" classes in the discipline: introduction to American government, introduction to comparative politics, introduction to international relations, and introduction to political theory. These courses are often the only exposure that many students have to the discipline and, as such, will motivate students to take additional political science classes (or not) and choose political science as a major (or not). With many departments facing tight budgets, boosting enrollment and attracting majors are benefits beyond the strictly pedagogical that active learning can offer.

After briefly reviewing the benefits of active learning, we describe our analysis of 491 introductory-level course syllabi and their prioritization of active learning. While syllabi cannot fully 
convey what occurs in the classroom, they do provide a summary statement of instructor intentions, desired learning outcomes, and pedagogical approaches. Our multi-class, multi-subfield approach thus complements existing literature that focuses at a more detailed level on individual instructor and student experiences in individual classrooms.

\section{THE MERITS OF ACTIVE LEARNING}

Active learning techniques seem a natural fit for political science. The subject matter lends itself to discussion and debate, theories and decision-making can be evaluated in light of current events, and institutions such as Congress and the United Nations lend themselves easily to simulations. Unfortunately, introductory on exams than students in sections without them. Budesheim and Lundquist (1999) similarly found that structured, in-class debates promoted student learning, particularly among students assigned to argue positions contrary to their own beliefs.

Promoting critical thinking is a higher-order pedagogical goal of university instructors and is de rigueur on any list of course goals. Bonwell and Eison (1991) argue that active learning techniques effectively promote critical thinking by increasing students' ability to integrate material and apply concepts. Other scholars have found that specific techniques such as experiential learning; simulations; and structured, in-class debates promote deeper insights and stronger evaluative skills among students than do traditional lectures (Green and Klug 1990; Smith and Boyer

\section{However, the traditional lecture format should not be jettisoned merely because students find it impersonal. Traditional lecture and active learning techniques should be incorporated into instruction based on their likelihood of achieving specific pedagogical and practical goals and learning outcomes, such as advancing student learning, promoting critical thinking, and sparking interest in the major. In meeting both sets of goals-pedagogical and practical- active learning excels.}

classes are also likely to be large. First- and second-year enrollees often arrive on the first day with little content knowledge, and many students are nonmajors who are simply fulfilling a general education requirement. As such, instructors may feel compelled to rely on traditional lecture techniques to deliver content as efficiently as possible.

The traditional lecture format allows instructors to cover an array of topics quickly, assisted by introductory textbooks that usually contain between 14 and 16 chapters-one for each week of a standard introductory course. Lecture notes and accompanying PowerPoint presentations are ubiquitous in the introductory textbook market and readily provided by publishers. Under this approach, students often become "passive receptacles of information" (Miller and Archer 2011). Not surprisingly, studies show that students find lecture-style classes to be impersonal (Lewis and Woodward 1984; Wulff, Nyquist, and Abbott 1987).

However, the traditional lecture format should not be jettisoned merely because students find it impersonal. Traditional lecture and active learning techniques should be incorporated into instruction based on their likelihood of achieving specific pedagogical and practical goals and learning outcomes, such as advancing student learning, promoting critical thinking, and sparking interest in the major. In meeting both sets of goals-pedagogical and practical-active learning excels.

Understanding course content is a primary desired learning outcome of any introductory political science course. Studies in fields as diverse as psychology (e.g., Budesheim and Lundquist 1999), management and economics (e.g., Carlson and Schodt 1995), sociology (e.g., Green and Klug 1990), and political science (e.g., Frederking 2005; Shellman and Turan 2006) have found that students learn more when active learning techniques are employed. Frederking's (2005) experimental use of a simulation in an introductory American government class revealed, for instance, that students in sections using simulations scored significantly higher
1996; Shellman 2001; Dougherty 2003; Omelicheva and Avdeyeva 2008; Lightcap 2009).

Finally, retention of acquired knowledge is an important pedagogical goal of introductory political science courses, which often serve as prerequisites for upper-division courses that require prior mastery of core concepts. Active learning approaches have been shown to increase knowledge retention (Bonwell and Sutherland 1996). In terms of specific techniques, simulations and the case method have demonstrably promoted knowledge retention among students (Pace et al. 1990; Smith and Boyer 1996; Sudzina 1997).

On a practical level, many political science departments are currently facing reduced budgets. In this climate, departments may be concerned about maintaining or increasing their number of majors and encouraging enrollment among nonmajors. Stimulating subject interest, a desirable goal under any circumstances, may be even more important during periods of fiscal austerity. Studies show that active learning techniques increase interest in the subject under scrutiny (Green and Klug 1990; Hensley 1993; Dougherty 2003; Mariani 2007) and attract majors to the discipline (Fox and Ronkowski 1997; Shellman and Turan 2006). As such, a compelling case can be made for adopting active learning approaches in gateway political science courses in order to boost departmental enrollments.

Student satisfaction may be another practical goal in departments keen to boost enrollment. Student evaluations tend to be more favorable in classes that employ active learning approaches (Green and Klug 1990; Dougherty 2003; Frederking 2005). This effect may be especially pronounced in gateway courses, since students in lower-division classes prefer active learning techniques more than their upper-division counterparts (Fox and Ronkowski 1997).

In light of the evidence suggesting that active learning techniques promote both pedagogical and practical benefits, we here study the extent to which active learning is prioritized in gateway 
political science courses. We expected this approach to be fairly common: education researchers have asserted for over a decade that a "paradigm shift" toward active, student-centered learning is underway at many colleges and universities (Barr and Tagg 1995). On the other hand, we anticipated that the prioritization of active learning in introductory political science courses might be limited. Some instructors may worry that class size precludes the use of active learning techniques, and introductory courses are likely to be among the largest courses offered in any given department. We thus expected the prioritization of active learning to decrease as class size increased.

\section{METHOD}

To assess the prioritization of active learning in gateway political science courses, we systematically examined 491 individual course syllabi used in introductory political science courses taught at U.S. colleges and universities between 2000 and 2010. Syllabi were collected online using Google and the Syllabus Finder tool maintained by the Center for History and New Media at George Mason University. The latter is a search engine that allows users to access syllabi from thousands of colleges and universities.

We selected only syllabi for standard introductory courses in American politics, comparative politics, international relations (IR), and political theory for the sample. The search criteria accounted for variations in course names so that courses with titles such as "Introduction to American Politics," "Intro. to American Government," "American Government \& Politics," and so forth would be included. Ultimately, a total of 139 American politics syllabi, 135 comparative politics syllabi, 138 IR syllabi, and 79 political theory syllabi were collected and analyzed. ${ }^{1}$

A total of 238 individual colleges and universities are represented in the sample of course syllabi. ${ }^{2,3}$ Among all 491 syllabi in the sample, $66.1 \%$ were drawn from public institutions and $33.9 \%$ from private institutions. A greater percentage of the syllabi came from Ph.D.-granting institutions (72.7\%) than non-Ph.D.-granting institutions (27.4\%). The pronounced representation of Ph.D.granting institutions in the dataset may indicate that larger institutions-which are more likely to offer doctoral degrees-are more likely than their smaller counterparts to make course materials available online.

For each syllabus, we recorded the presence or absence of three specific active learning techniques: simulations, structured debates, ${ }^{4}$ and the case method. ${ }^{5}$ In addition, we noted the proportion of the final course grade that was contingent on active learning (\% active learning), as measured through either one of these three specific techniques or a broader "class discussion" or "participation" grade.

The prioritization of active learning may vary on a number of different dimensions. Dimensions used included subfield (American politics/comparative politics/IR/political theory), instructor gender (female/male), and course delivery method (on-line/in person). We also recorded the following proxies for class size: institutional size (indicated by student/faculty ratio), institutional type (public/private), highest degree awarded by the institution (Ph.D. awarded/Ph.D. not awarded), and section model employed (individual section/discussion sections). Class size was assumed to be larger at institutions with higher student/faculty ratios, public institutions, and Ph.D.-granting institutions, and in courses employing an individual section model. ${ }^{6}$

Two limitations to the study are worth noting prior to presenting our findings. First, because of the nonrandom nature of data collection, the findings are suggestive of trends in the teaching of political science gateway courses but cannot be generalized beyond the sample. Second, the measures of active learning employed act as proxies for instructor prioritization of the pedagogy. They do not measure actual time devoted to active learning in the classroom. We elaborate on both of these limitations in the discussion section.

\section{ACTIVE LEARNING IN GATEWAY COURSES}

The use of active learning techniques does not appear to be frequent in the gateway political science courses included in the sample. Figure 1 displays the percentage of courses using simulations, structured debates, and the case method. Simulations were employed most often but were still used in fewer than $8 \%$ of gateway courses in the sample. Structured debates and the case method were employed at even lower rates. Overall, $14.7 \%$ of all gateway courses in the sample employed one or more of these three active learning techniques.

Subfield and course delivery method proved to be the only dimensions on which the use of simulations, structured debates, and/or the case method varied significantly. IR courses were disproportionately likely to incorporate one or more of these specific active learning techniques (24.6\%), followed by American politics (12.9\%), comparative politics (11.1\%), and political theory (6.3\%) courses. This disparity is largely explained by IR courses' disproportionate use of the case method. Introductory IR courses were significantly more likely to employ the case method (10.9\%) than were introductory comparative politics (1.5\%), American politics $(0.7 \%)$, or political theory $(0 \%)$ courses.

Courses delivered online were significantly more likely to incorporate simulations $(25.0 \%)$ than courses delivered in person (7.2\%). However, the propensity of online courses to include one or more of the specific active learning techniques tested was not significantly different from that of courses delivered in the traditional, in-person format. 
Figure 2

\section{Average Course Grade Allocation (\% of Course Grade Devoted to Each Component)}

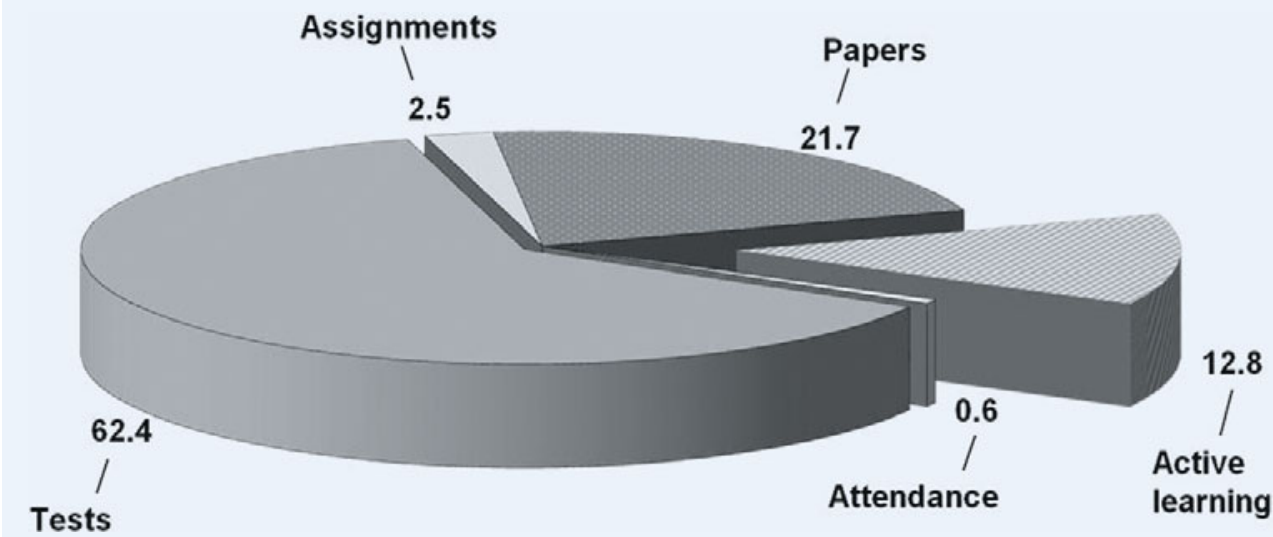

Tests

Note. $N=491$ syllabi (American politics: $n=139$; comparative politics: $n=135$; international relations: $n=138$; political theory $n=79$ ).

In addition to coding whether specific techniques were employed in each course, we also recorded the percentage of the final course grade that was contingent on active learning. Boud claims that "every act of assessment gives a message to students about what they should be learning" $(1995,39)$. Similarly, Omelicheva and Avdeyeva note that "students are typically more motivated to invest their intellectual energy in solving complex problems when they know that their work will be graded" (2008). Thus, active learning assessment indicates both whether the instructor prioritizes the pedagogy and whether student learning will be advanced as a result.

While a full $77 \%$ of all gateway courses in the sample include active learning in the final course grade calculation (at $1 \%$ or more of the final grade), this finding masks a very different underlying reality. Many courses (23\%) fail to assess active learning at all, and more than half (50.8\%) that do combine active learning with mundane indicators of student performance such as attendance and quizzes. A typical American politics syllabus advises students that attendance and participation will count as $10 \%$ of the final grade. One comparative politics syllabus went so far as to collapse student "initiative," "collaborativeness," and "involvement" with "presence, punctuality, ... homework submitted in a timely fashion, performance on announced and unannounced quizzes ... [and] intellectual growth and impact on class" into a single category. Together, these elements constitute $3 \%$ of the final grade.

On average, only $12.8 \%$ of the final course grades across all 491 course syllabi are contingent on active learning (see figure 2). This percentage compares with $62.4 \%$ of the final course grade that is contingent on tests and $21.7 \%$ that is contingent on research papers and/or essays. Taken together, the results suggest that the prioritization of active learning in gateway political science courses tends to be relatively low.

Nevertheless, there are several dimensions on which greater prioritization of active learning is apparent. These areas are noted in table 1 , which displays the average percentage of the final course grade that is devoted to active learning across various dimensions.

In keeping with the findings reported here on specific active learning techniques, IR courses tend to place a higher priority on active learning in terms of assessment. On average, $14.2 \%$ of the final grade in IR gateway courses is devoted to active learning. This average rate is significantly higher than the rate reported for American politics courses (11.3\%), although it is not significantly different from the rate for comparative politics and political theory courses (12.9\%).

Other dimensions on which active learning assessment varied significantly appear to tap into class size. Courses organized with (presumably smaller) weekly discussion sections devoted an average of $15.9 \%$ of the final grade to active learning, in contrast with $11.9 \%$ of the final grade in courses organized in single sections. This difference is ironic, given that active learning assessment made up less of the final course grade (12.2\%) at schools with high student/faculty ratios-presumably, large institutions that are likely to offer large introductory courses organized on the discussion section model. Institutions with low student/faculty ratios-and, presumably, smaller classes-devoted a significantly higher proportion of the final grade to active learning (13.9\%).

Institutional type also showed a significant relationship with active learning assessment. Gateway political science courses offered at private institutions assessed active learning at a higher rate $(15.1 \%)$ than gateway political science courses offered at public institutions (11.7\%). The average student/faculty ratio for the private universities in the sample was 10.3 to 1 ; this ratio was significantly higher for the public universities in the sample (16.9 to 1). Thus, the relationship between active learning assessment and institutional type may partially reflect differences in student/faculty ratios, again suggesting that class size is likely a factor.

Finally, it should be noted that active learning assessment did not vary significantly by instructor gender, course delivery method, or highest degree awarded.

\section{DISCUSSION}

Research suggests that the use of active learning techniques can enhance introductory political science courses by promoting student learning, critical thinking, and subject matter interest, thereby attracting majors and benefiting students and faculty. Unfortunately, findings from our sample of nearly 500 course syllabi suggest that active learning is not highly prioritized in introductory political science courses. Specific findings suggest that active learning does vary by subfield and across various proxies for class size. In each case, the reasons for disproportionately low use of these techniques are understandable and suggest means by which more extensive adoption might be promoted.

The prioritization of active learning varies by subfield. The proportion of the final course grade devoted to active learning was significantly higher in gateway IR courses than in gateway American politics courses, although there were no statistically 
Table 1

\section{Proportion of Final Course Grade Devoted to Active Learning}

\begin{tabular}{|c|c|c|}
\hline & $\begin{array}{l}\text { MEAN PERCENTAGE } \\
\text { OF FINAL COURSE } \\
\text { GRADE DEVOTED } \\
\text { TO ACTIVE LEARNING }\end{array}$ & $\begin{array}{l}\text { NUMBER } \\
\text { OF SYLLABI }\end{array}$ \\
\hline \multicolumn{3}{|l|}{ Subfield } \\
\hline American Politics & $11.3^{*, a}$ & 139 \\
\hline Comparative Politics & 12.9 & 135 \\
\hline International Relations & 14.2 & 138 \\
\hline Political Theory & 12.9 & 79 \\
\hline \multicolumn{3}{|l|}{ Instructor Gender } \\
\hline Female & 12.0 & 130 \\
\hline Male & 13.1 & 360 \\
\hline \multicolumn{3}{|l|}{ Course Delivery Method } \\
\hline Online & 11.7 & 16 \\
\hline In Person & 12.8 & 475 \\
\hline \multicolumn{3}{|l|}{ Section Model } \\
\hline Single Section & $11.9 * * *$ & 377 \\
\hline Discussion Sections & 15.9 & 114 \\
\hline \multicolumn{3}{|l|}{ Institutional Size } \\
\hline Low Student-Faculty Ratio & $13.9 *$ & 206 \\
\hline High Student-Faculty Ratio & 12.2 & 256 \\
\hline \multicolumn{3}{|l|}{ Institutional Type } \\
\hline Public & $11.7^{* * *}$ & 324 \\
\hline Private & 15.1 & 166 \\
\hline \multicolumn{3}{|l|}{ Degree Awarded } \\
\hline Ph.D. Granted by Institution & 12.7 & 356 \\
\hline Ph.D. Not Granted & 13.1 & 134 \\
\hline All Courses & 12.8 & 491 \\
\hline \multicolumn{3}{|c|}{ 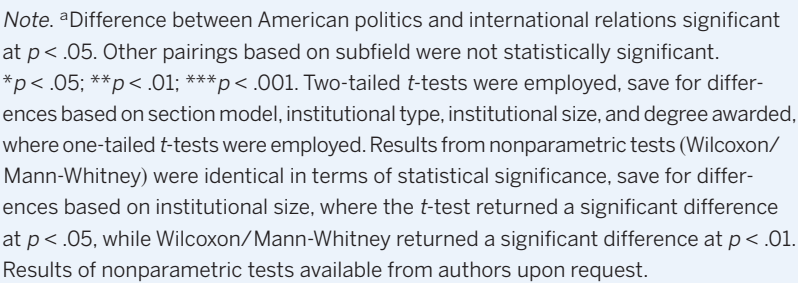 } \\
\hline
\end{tabular}

significant differences when compared with comparative politics and political theory courses. Gateway IR courses, however, incorporated case studies at a much higher and statistically significant rate than did the other subfields. This tendency may stem in part from a movement launched by the Pew Foundation in the early 1990 s to train international affairs scholars in the case study method. Approximately 120 of these scholars visited Harvard's John F. Kennedy School of Government for training in the technique and were taught how to educate their graduate students and colleagues about it. It is also possible that case studies pertaining to IR are more readily available than case studies suited for other subfields. Likewise, the wide availability of online simulation programs may help to explain their disproportionate use in courses delivered online. Instructors of online courses may also have an extra incentive to engage students in course material.
The use of active learning varies by several proxies for class size: student/faculty ratio, single or discussion section model, and public or private institution. In each case, there is an inverse relationship between the prioritization of active learning and class size. To be sure, introductory political science classes are frequently the largest classes offered in most departments. This reality should not preclude the adoption of active learning approaches, however. Some scholars argue that students in introductory classes prefer active learning (Fox and Ronkowski 1997), while others assert that class size does not preclude adoption of these techniques (Green and Klug 1990; Golich et al. 2000). In fact, large, introductory classes may be ideally suited to active learning when implemented in the form of collaborative group projects or structured debates. This kind of work may be easier for instructors to grade than either scores of individual papers (Green and Klug 1990) or participation in class discussion over an entire term.

Elsewhere, we detail specific strategies for introducing the case method into introductory American politics courses (Miller and Archer 2011), including tips for creating a small-class environment, discouraging "free riders," and keeping track of individual participants. These techniques can easily be applied to other forms of active learning, such as simulations and structured debates. In short, class size is not an insurmountable obstacle to the adoption of active learning techniques in introductory political science courses.

It stands to reason that instructors who are familiar with active learning will be more willing to adopt this approach than instructors who are unfamiliar. Thus, the numerous articles in this journal and others that provide detailed descriptions of how to run a simulation, lead a case study, or structure an in-class debate are valuable resources, since they may encourage adoption.

Two limitations to our study should be noted. First, we used a nonprobability sample of course syllabi that were available online. This data source biases our results in favor of "posted" syllabi. We therefore caution readers about the generalizability of our results. It could be that instructors who are more innovative in their use of active learning are also more innovative in making course materials available over the web. If so, our results would be biased in favor of active learning. Further research employing random sampling would certainly be worthwhile.

Second, one of our key variables measures the percentage of the final course grade that is contingent on active learning. Active learning may be occurring in introductory classes without being assessed. If so, our results would be biased against active learning. Firsthand observation of gateway courses might reveal that active learning techniques are employed more often than we suggest. Such in-depth, qualitative study is recommended for future research. Our study does, however, indicate what instructors tend to value as they construct their classes and what they signal to students as being important enough to assess. This work also provides a broad overview of the prioritization of active learning in gateway classes at institutions across the United States.

Neither our findings nor our implicit recommendation to adopt active learning should be interpreted to mean that $100 \%$ of the final course grade in an introductory-level course should be contingent on participation in simulations, case discussions, or other active learning exercises. Omelicheva and Avdeyeva have compared the effectiveness of traditional versus active learning methods of instruction and concluded that "a combination of both the 
conventional and active-learning curricula may provide the most effective training for undergraduate students" (2008, 606). We agree wholeheartedly.

\section{NOTES}

1. Additional online search methods were adopted to obtain political theory syllabi, including direct searches of departmental websites for specific introductory-level political theory course syllabi.

2. The sample includes syllabi from community colleges (e.g., Anne Arundel Community College, Fort Scott Community College), liberal arts colleges (e.g., Gustavus Adolphus College, Pomona College), and universities (e.g., Lehigh University, University of Georgia). A complete list of all colleges and universities in the sample is available from the authors on request.

3. Some institutions are associated with multiple syllabi in the sample, since online syllabi were sometimes available for different introductory-level course at a single institution (e.g., "Introduction to International Relations" and "Introduction to American Government"). In addition, different syllabi for the same course were sometimes available for different semesters or different faculty members.

4. Structured debates are distinguished from informal debates that might arise during routine class discussions. In contrast, structured debates are scheduled, students are assigned to argue a specific point of view, and advance preparation is expected. For examples of structured debate formats, see Budesheim and Lundquist (1999), Green and Klug (1990), and Bauer and Wachowiak (1977).

5. We differentiate between the case method and the use of case studies in comparative politics work. In the latter, countries are often presented as "cases" to exemplify institutions or specific concepts such as proportional representation. We define case studies here as detailed explications of real-life events that force students to consider the resources and options available to participants. Our definition is consistent with the Pew Foundation's case study initiative (see Golich et al. 200o).

6. Courses employing an individual section model may actually have lower enrollments than those employing a discussion section model. However, we conceptualized courses that use a discussion section model as smaller in terms of class size, since these classes build a small, weekly discussion section into course design.

\section{REF EREN C ES}

Barr, Robert B., and John Tagg. 1995. "From Teaching to Learning: A New Paradigm for Undergraduate Education." Change 27 (6): 13-25.

Bauer, Gene, and Dale Wachowiak. 1977. "The Home-court Advantage: A Debate Format for the Teaching of Personality." Teaching of Psychology 4: 190-3.

Bonwell, Charles C., and J. Eison. 1991. Active Learning: Creating Excitement in the Classroom. AEHE-ERIC Higher Education Report No. 1. Washington, DC: Jossey-Bass.

Bonwell, Charles, and Tracey E. Sutherland. 1996. "The Active Learning Continuum: Choosing Active Learning to Engage Students in the Classroom." New Directions for Teaching and Learning 67:3-16.

Boud, David. 1995. "Assessment and Learning: Contradictory or Complementary? In Assessment for Learning in Higher Education, ed. Peter Knight, 35-48. London: RoutledgeFalmer.

Budesheim, Thomas Lee, and Arlene R. Lundquist. 1999. "Consider the Opposite: Opening Minds through In-class Debates on Course-related Controversies." Teaching of Psychology 26: 106-10.

Burch, Kurt. 2000. "A Primer on Problem-Based Learning for International Relations Courses." International Studies Perspectives 1: 31-44.
Carlson, John A., and David W. Schodt. 1995. "Beyond the Lecture: Case Teaching and the Learning of Economic Theory." Journal of Economic Education 26: 17-28.

Dougherty, Beth. 2003. "Byzantine Politics: Using Simulations to Make Sense of the Middle East." PS: Political Science \& Politics 36: 239-44.

Fox, Richard L., and Shirley A. Ronkowski. 1997. "Learning Styles of Political Science Students." PS: Political Science \& Politics 30: 732-37.

Frederking, Brian. 2005. "Simulations and Student Learning." Journal of Political Science Education 1: 385-93.

Golich, Vicki L., Mark Boyer, Patrice Franko, and Steve Lamy. 20oo. The ABCs of Case Teaching: Pew Case Studies in International Affairs. Washington, DC: Institute for the Study of Diplomacy.

Green, Charles S., and Hadley G. Klug. 1990. "Teaching Critical Thinking and Writing through Debates: An Experimental Evaluation." Teaching Sociology 18: 462-71.

Hensley, Thomas R. 1993. "Come to the Edge: Role Playing Activities in a Constitutional Law Class." PS: Political Science and Politics 26: 64-68.

Hoffman, Donna R. 2009. "Representation and the Rules of the Game: An Electoral Simulation." PS: Political Science \& Politics 42: 531-35.

Kelle, Alexander. 2008. "Experiential Learning in an Arms Control Simulation." PS: Political Science \& Politics 41: 379-85.

Lantis, Jeffrey S., Lynn M. Kuzma, and John Boehrer, eds. 20oo. The New International Studies Classroom: Active Teaching, Active Learning. New York: Lynne Rienner.

Lewis, Karron G., and Paul J. Woodward. 1984. "What Really Happens in Large University Classes?" Paper presented at the 68th Annual Meeting of the American Educational Research Association, New Orleans, LA, April 23-27.

Lightcap, Tracy. 2009. "Creating Political Order: Maintaining Student Engagement through Reacting to the Past." PS: Political Science \& Politics 42: 175-79.

Loggins, Julie A. 2009. "Simulating the Foreign Policy Decision-Making Process in the Undergraduate Classroom." PS: Political Science \& Politics 42: 401-07.

Mariani, Mack D. 2007. "Connecting Student to Politics through a Multi-Class Campaign Simulation." PS: Political Science \& Politics 40: 789-94.

Meyers, C., and T. B. Jones. 1993. Promoting Active Learning Strategies for the College Classroom. San Francisco: Jossey-Bass.

Miller, Melissa K., and Candace C. Archer. 2011. "Making the Case for Case Studies." In Teaching Matters: Strategy and Tactics to Engage Students in the Study of American Politics, ed. Daniel Shea. New York: Pearson/Longman.

Omelicheva, Mariya, and Olga Avdeyeva. 2008. "Teaching with Lecture or Debate? Testing the Effectiveness of Traditional Versus Active Learning Methods of Instruction." PS: Political Science \& Politics 41: 603-07.

Pace, David, Bill Bishel, Roger Beck, Peter Holquist, and George Makowski. 1990. "Structure and Spontaneity: Pedagogical Tensions in the Construction of a Simulation of the Cuban Missile Crisis." History Teacher 24: 53-65.

Shellman, Stephen M. 2001. "Active Learning in Comparative Politics: A Mock German Election and Coalition-Formation Simulation." PS: Political Science and Politics 34: 827-34.

Shellman, Stephen M., and Kürsad Turan. 2006. "Do Simulations Enhance Student Learning? An Empirical Evaluation of an IR Simulation." Journal of Political Science Education 2: 19-32.

Smith, Elizabeth, and Mark A. Boyer. 1996. "Designing In-Class Simulations." PS: Political Science \& Politics 29: 690-94.

Sudzina, Mary R. 1997. "Case Study as a Constructivist Pedagogy for Teaching Educational Psychology.” Educational Psychology Review 9: 199-260.

Wulff, D. H., J. D. Nyquist, and R. D. Abbott. 1987. "Students' Perceptions of Large Classes." In Teaching Large Classes Well, Vol. 32, ed. M. G. Weimer, 17-30. New Directions for Teaching and Learning. San Francisco: Jossey-Bass. 